\title{
Protective Effect of Fish Oil and Virgin Olive Oil on Diethylnitrosamine Toxicity in Rats
}

\author{
Naglaa H. M. Hassanen, Mona H. M. Ahmed \\ Special Food and Nutrition Department, Food Technology Research Institute, Agricultural Researches Center, Giza, Egypt
}

Email address:

naglaahassanen@yahoo.com (N. H. M. Hassanen), monahanafiahmed@yahoo.com (M. H. M. Ahmed)

To cite this article:

Naglaa H. M. Hassanen, Mona H. M. Ahmed. Protective Effect of Fish Oil and Virgin Olive Oil on Diethylnitrosamine Toxicity in Rats. International Journal of Nutrition and Food Sciences. Vol. 4, No. 3, 2015, pp. 388-396. doi: 10.11648/j.ijnfs.20150403.27

\begin{abstract}
Liver injury induced by viruses, toxic chemicals, certain drugs and environmental pollutants, has been on the increase for the past few decades and recognized as a toxicological problem. Nitrosamine compounds are known hepatic carcinogens. The present study was carried out to investigate the hepatoprotective effect of fish oil and virgin olive oil against diethylnitrosamine (DEN) intoxication in rats compared with drug $(25 \mathrm{mg} / \mathrm{kg} \mathrm{diet})$. Wister rats weighing $200 \pm 5 \mathrm{~g}$ were induced hepatotoxicity by injection of DEN (via single intraperitoneally injection at $150 \mathrm{mg} / \mathrm{kg} /$ body weight). Rats were divided into 9 groups $(n=6)$ of non- hepatotoxicity, non- hepatotoxicity and treated, hepatotoxicity non-treated and hepatotoxicity treated with drug, fish oil, virgin olive oil. After 8 weeks the rats feeding with fish oil, virgin olive oil supplied to hepatotoxicity rats instead of diet significant improvement in lipid profile and liver function. However, a significantly increment in the activities of superoxide dismutase (SOD), catalase (CAT), glutathione peroxidase (GSPx) and glutathione reduced (GSH) were observed in blood of hepatotoxicity rats treated with fish oil, virgin olive oil and mixtures. The treated groups showed a significant decrement in thiobarbituric acid reactive substances (MDA) in serum. Since the study of induction of the redox enzymes is considered to be a reliable marker for evaluating the antiperoxidative efficacy of the fish oil and virgin olive oil. Treatment with fish oil and virgin olive oil reduces the histopathological liver abnormalities associated with hepatotoxicity. Moreover to the anti hepatotoxicity effect and possess antioxidant potential that may be used for therapeutic purposes suggested. The present study showed that fish oil, virgin olive oil were able to prevent or reduce the severity of diethylnitrosamine -induced liver injury.
\end{abstract}

Keywords: Diethylnitrosamine, Fish Oil, Virgin Olive Oil, Hepatotoprotective, Lipid Profile, Function Liver, SOD, CAT, GSPx, GSH, MDA, Histopathological Liver

\section{Introduction}

N-nitroso compounds are environmental toxicants, which are widely used in industrial solvents. They are also known as carcinogens and could be found in different types of foodstuff including milk, meat, salted fish, alcoholic beverages and several vegetables [1]. Both environmental and food born .N-nitrosamines pose a health risk for human and animals. Diethylnitrosamine is experimentally used to induce liver carcinoma and study the mechanisms of cytotoxic injury. The cytochrome P-450 - dependent enzymes of monooxygenase system also catalyze diethylnitrosamine. Some of the byproducts produced during these reactions react covalently with cellular components leading to cellular necrosis, mutation and cancer [2]. DEN is reported to induce generation of free radicals leading to oxidative stress and cell injury through its metabolized end product (ethyl radical).
The action of active metabolite ethyl radical on DNA is considered to play a role in carcinogenesis [3]. DEN causes alterations in some enzymes found in the serum and tissues. When the liver cells are injured, several types of liver-specific enzymes, including aspartate aminotransferase (AST), alanine aminotransferase (ALT) and alkaline phospatase (ALP) are elevated. Studies indicated that DEN elevates the activities of these enzymes [4]. AST, ALT and ALP are the group of enzymes, which are used to evaluate the status of liver damage and are considered more sensitive parameters to assess liver injury in rodent species [5]. It is known that one of the major mediators in chronic inflammatory processes is the nitrite oxide (NO). It is produced by the liver parenchymal and non-parenchymal cells from L-arginine via nitric oxide synthase (NOS) [6]. In 
normal physiological conditions, NO could be either protective or cytotoxic. Uncontrolled, prolonged and/or massive production of NO by inducible NOS (iNOS) may cause liver damage, inflammation and even tumour development [7]. Biologically important long chain omega-3 polyunsaturated fatty acids, including eicosapentaenoic acid (EPA), docosahexaenoic acid (DHA) and $\alpha$-linoleic acid (ALA), exist in large amounts in fish and fish oils [8] . Recent studies indicate that n-3 fatty acids could have beneficial effects on cancer, cardio-vascular diseases, immune system, cirrhosis and nervous system disorders [9, 10 and 11]. In addition, omega-3 essential fatty acids are reported to have antioxidant properties by reducing oxidative stress and preventing generation of reactive oxygen species (ROS) [12 and 13].

The Mediterranean diet, associated for centuries with human health benefits, emphasizes whole grains, fruits, vegetables, and olive oil as the major source of dietary fat. Studies have confirmed that consumption of olive oil reduces the risk of developing chronic diseases such as cancer and heart disease [14]. The benefits of olive oil include reducing DNA oxidation and a favorable influence on cholesterol regulation and low-density lipoprotein oxidation, as well as anti-inflammatory, antithrombotic, antihypertensive, and vasodilatory effects [15]. The mechanism proposed to explain the positive effects of olive oil may be attributed to its abundant concentration of the monounsaturated fat, oleic acid [16], and polyphenolic constituents [17] that differ depending on the variety, the soil, the climate, and the way the oil is produced and stored. Olive oil polyphenols have been shown to exhibit strong antioxidant properties [18]. Therefore, regular consumption of this oil in the diet provides a constant supply of potential antioxidants that could reduce oxidative stress through the inhibition of lipid peroxidation, a factor that is currently linked to a host of diseases and scavenging of free radicals [19].

It was the aim of this work to explore the hepatoprotective effect of fish oil and olive oil, against DEN -Induced Liver Injury in Rats.

\section{Materials and Methods}

Virgin olive oil was purchased from Food Technology Research Institute, Agricultural Researches Center, Giza, Egypt.

Fish oil and Silymarin were purchased from pharmacy.

Diethylnitrosamine (DEN): Diethylnitrosamine (99.9 purity) was purchased from Sigma Chemical Company. DEN (via single intraperitoneally injection at $150 \mathrm{mg} / \mathrm{kg} /$ body weight) [4].

Fatty acids were determined according to the methods described by [20].

Animals: Fifty four male Wister rats, average weight of $200 \pm 5$ g. raised in the animal house of the Ophthalmology Research Institute, Giza, Egypt, were used in the present study. The rats were kept under normal healthy laboratory condition; temperature was adjusted at $25 \pm 2{ }^{\circ} \mathrm{C}$ and 12 hour light - dark.
Animals were adapted on free access of water, and fed for one week basal diet before the initiation standard of the experimental. Composition of the basal diet $(\mathrm{g} / \mathrm{kg})$ : Casein, $10 \%$;cellulose, $5 \%$;sunflower oil, $10 \%$; corn starch ,70\% ; salt mixture, $4 \%$ and vitamin mixture, $1 \%$ according to [21,22 and 23 , respectively].

\subsection{Experimental Design}

Nine equal groups each of six rates were housed in wire cages in a room temperature maintained at $25 \mathrm{oC} \pm 2$ and kept under normal healthy conditions. All rats and food consumption weight every week for determination the body weight gain. Rats of first group (NI) kept as control negative (normal control) and fed on basal ration. Rats of the second group (N2) were used as positive control, fed on basal ration and was injected by (via single intraperitoneally injection at $150 \mathrm{mg} / \mathrm{kg} /$ body weight) DEN [4]. Rats of the third group (N3) fed on basal ration mixed with silymarin at concentration $(25 \mathrm{mg} / \mathrm{kg}$ diet $)$ for 60 successive days and at same time injected single intraperitoneally by $(150$ $\mathrm{mg} / \mathrm{kg} /$ body weight) DEN. Rats of the fourth group (N4) fed on basal ration mixed with fish oil at concentration $5 \mathrm{~g} / 100 \mathrm{~g}$ diet for 60 successive days. The fifth Group (N5) fed on basal ration mixed with virgin olive oil at concentration $2 \mathrm{~g} / 100 \mathrm{~g}$ diet for 60 successive days. The sixth group (N6) was fed on basal ration mixed with mixtures fish oil and virgin olive oil at concentration $5 \mathrm{~g} / 100 \mathrm{~g}$ diet for 60 successive days. Rats of seventh group (N7) were fed on basal ration mixed with fish oil at concentration $5 \mathrm{~g} / 100 \mathrm{~g}$ diet for 60 successive days and at same time injected single intraperitoneally by $(150 \mathrm{mg} / \mathrm{kg} /$ body weight $)$ DEN [24]. The eight group (N8) were fed on basal ration mixed with virgin olive oil at concentration $5 \mathrm{~g} / 100 \mathrm{~g}$ diet for 60 successive days and at same time injected single intraperitoneally by (150 mg/kg/body weight) DEN [19]. Rats of nine group (N9) were fed on basal ration mixed with fish oil and virgin olive oil at concentration $5 \mathrm{~g} / 100 \mathrm{~g}$ diet for 60 successive days and at same time injected single intraperitoneally by $(150 \mathrm{mg} / \mathrm{kg} /$ body weight $) \mathrm{DEN}$.

\subsection{Growth of Rats}

The gain in the body weights was calculated by the body weight gain $=$ final weight- initial weight.

\subsection{Biochemical Assay}

At the end of experimental period, blood samples were collected from the animals from the eye plexuses on ice. Each sample was collected into both heparinized tubes to obtain the plasma and into a dry clean centrifuge glass tube without any coagulation to prepare serum. Blood was left for15 $\mathrm{min}$ at room temperature, then the tubes were centrifugation for $15 \mathrm{~min}$ at $3000 \mathrm{rpm}$ and the clean supernatant serum was kept frozen at $-20{ }^{\circ} \mathrm{C}$ until the time of analysis. Serum total cholesterol (TC.), high density lipoprotein (HDL), low density lipoprotein (LDL), VLDLcholesterol and triglycerides (TG.) were determined by using 
the methods described by $[25,26,27,28$ and 29, respectively]. Liver function in serum: Alanine aminotransferase (ALT) and aspartate aminotransferase (AST) activities were assayed by the method of [30]. Alkaline phosphatase (ALP) activity was measured at 405 $\mathrm{nm}$ by the formation of paranitrophenol from para-nitrophenylphosphate as a substrate using the method of [31]. Total protein, albumin and total bilirubin were determined by using the methods described by [32, 33 and 34 , respectively]. The activity of lipid peroxidation level (Malondialdehyde, MDA) was determined in serum by the colorimetric method described by [35]. Superoxide dismutase (SOD), catalase (CAT), glutathione peroxides (GSHPx) and glutathione reduced (GSH) were measured calorimetrically in erythrocyte according to the method of [36, 37, 38 and 39, respectively].

\subsection{Histopathological Examination}

Sample from the liver was collected from rats in all groups at the end of experiments (60 days), fixed in $10 \%$ neutral buffered formalin, dehydrated in alcohol, cleared in xylol and embedded in paraffin. $4 \mu$ thick sections were prepared and stained with Hematoxylene and Eosin [40].

\subsection{Statistical Analysis}

The obtained results were subjected to statistical analysis using the standard analysis of variance as outlined by [41].

\section{Results and Discussion}

The present study was carried out to elucidate the chemical composition of oils, nutritional and protective effect of fish oil and virgin olive oil in normal and on diethylnitrosamine (DEN) induced cytogenicity and liver injury, using fish and olive oils for 60 days in male Wister rats. The tested parameters were chemical constituents and histopathological examination of liver in normal rats and rats injected with DEN. Their effects and constituents are registered in tables and Photographs.

Fatty acid composition of the fish oil and virgin olive oil: The fatty acid composition of the fish oil and virgin olive oil is presented in Table (1). The results show that in fish oil and virgin olive oil, there were decreases in linoleic acid (18:2) compared to control standard diet. Moreover, diet supplementation with virgin olive oil, a source of monounsaturated fat (oleic acid) rich in antioxidants, is able to reduce the oxidative damage caused by DEN, [19]. Meanwhile, fish oil sours of omega-3 polyunsaturated fatty acids, including eicosapentaenoic acid (EPA), docosahexaenoic acid (DHA). These results agree with that [4].

Table (1). Fatty acid composition of fish oil, virgin olive oil and standard diets fed to rats.

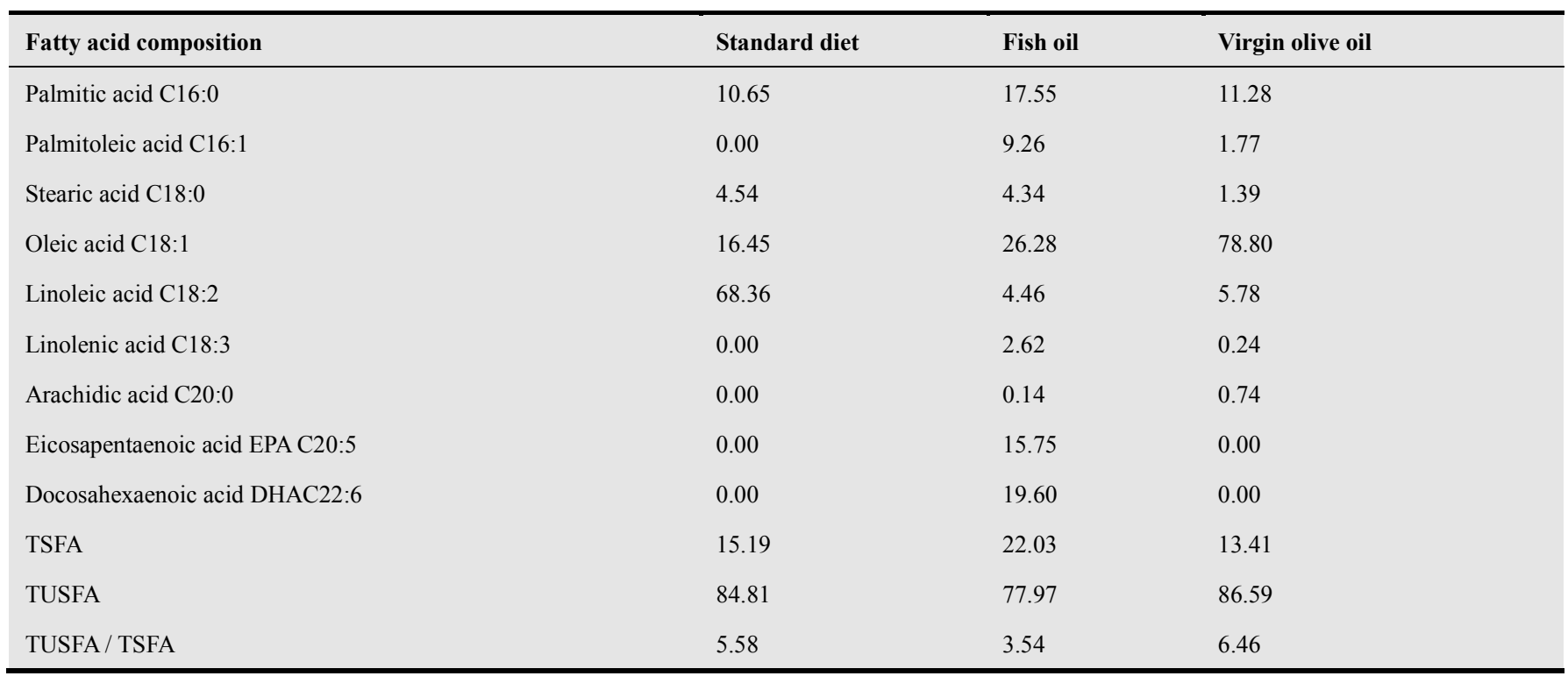

TUSFA: Total unsaturated fatty acid TSFA: Total saturated fatty acid.

TUSFA / TSFA: Ratio between total unsaturated to total saturate fatty acids.

Effect of fish oil and virgin olive oil on body weight gain and liver weight of experimental injected with den rats: Data presented in Table (2) show that initial body weights did not significantly differ among the groups and effect of feeding on ration mixed with fish oil and virgin olive oil and mixtures at $5 \mathrm{~g} / 100 \mathrm{~g}$ diet, respectively for 60 successive days with or without injection of diethylnitrosamine( DEN) (via single intraperitoneally injection at $150 \mathrm{mg} / \mathrm{kg} /$ body weight) on body weight gain are recorded in the same Table. Body weight gain was significantly increased in rats feed on ration mixed with fish oil and virgin olive oil and mixtures when compared with other groups, these findings correlated with those obtained by [19 and 42] while the group injected DEN showed significantly decreased $(75.78 \%)$ in the body weight gain as compared to control group (N1) [24]. The reduction of body weight gain observed in DEN treated animals may be due to losses of skeletal muscle and adipose tissue as mentioned by [43] and it could be considered as an indirect 
indication of the declining hepatic function following exposure to DEN.

Table (2). Effect of fish oil and virgin olive oil on body weight gain, Food intake and\% liver in experimental injected with DEN rats.

\begin{tabular}{llllllll}
\hline Treatments & Initial (g) & Final (g) & Weight gain & Food intake & $\begin{array}{l}\text { Feed efficiency } \\
\text { ratio (FER) }\end{array}$ & Liver (g) & Liver\% \\
\hline N1 (Control normal) & $200.6^{\mathrm{a}} \pm 2.60$ & $268.5^{\mathrm{f}} \pm 2.53$ & $67.93^{\mathrm{e}} \pm 0.07$ & $1033^{\mathrm{c}} \pm 13.50$ & $0.066^{\mathrm{ab}} \pm 0.001$ & $6.610^{\mathrm{e}} \pm 1.295$ & $2.46^{\mathrm{cde}} \pm 0.46$ \\
N2 (control DEN) & $201.2^{\mathrm{a}} \pm 4.20$ & $217.6^{\mathrm{i}} \pm 5.65$ & $16.45^{\mathrm{h}} \pm 1.45$ & $859^{\mathrm{g}} \pm 19.00$ & $0.019^{\mathrm{d}} \pm 0.001$ & $11.61^{\mathrm{a}} \pm 1.015$ & $5.33^{\mathrm{a}} \pm 0.33$ \\
N3 & $200.6^{\mathrm{a}} \pm 1.55$ & $244.8^{\mathrm{h}} \pm 4.83$ & $44.28^{\mathrm{g}} \pm 3.28$ & $910^{\mathrm{f}} \pm 10.00$ & $0.048^{\mathrm{c}} \pm 0.004$ & $8.757^{\mathrm{b}} \pm 1.565$ & $3.57^{\mathrm{b}} \pm 0.57$ \\
N4 & $200.9^{\mathrm{a}} \pm 2.90$ & $285.8^{\mathrm{c}} \pm 4.75$ & $84.88^{\mathrm{c}} \pm 1.85$ & $940^{\mathrm{e}} \pm 40.50$ & $0.060^{\mathrm{bc}} \pm 0.005$ & $6.863^{\mathrm{de}} \pm 1.25$ & $2.40^{\mathrm{de} \pm 0.40}$ \\
N5 & $200.9^{\mathrm{a}} \pm 1.85$ & $296.6^{\mathrm{a}} \pm 6.60$ & $95.75^{\mathrm{a}} \pm 4.75$ & $974^{\mathrm{d}} \pm 14.00$ & $0.077^{\mathrm{ab}} \pm 0.007$ & $7.253^{\mathrm{cd}} \pm 1.465$ & $2.413^{\mathrm{de}} \pm 0.4$ \\
N6 & $201.4^{\mathrm{a}} \pm 5.45$ & $290.5^{\mathrm{b}} \pm 3.49$ & $89.04^{\mathrm{b}} \pm 1.96$ & $984^{\mathrm{d}} \pm 24.00$ & $0.072^{\mathrm{ab}} \pm 0.001$ & $6.83^{\mathrm{de}} \pm 1.095$ & $2.35^{\mathrm{e}} \pm 0.35$ \\
N7 & $201.1^{\mathrm{a}} \pm 4.15$ & $257.7^{\mathrm{g}} \pm 2.67$ & $56.52^{\mathrm{f}} \pm 1.48$ & $1123^{\mathrm{b}} \pm 43.00$ & $0.076^{\mathrm{ab}} \pm 0.001$ & $6.837^{\mathrm{de}} \pm 1.745$ & $2.65^{\mathrm{cd}} \pm 0.65$ \\
N8 & $200.9^{\mathrm{a}} \pm 3.85$ & $279.7^{\mathrm{d}} \pm 1.73$ & $78.88^{\mathrm{d}} \pm 2.12$ & $1179^{\mathrm{a}} \pm 39.00$ & $0.081^{\mathrm{a}} \pm 0.002$ & $7.587^{\mathrm{c}} \pm 2.030$ & $2.71^{\mathrm{c}} \pm 0.71$ \\
N9 & $201.4^{\mathrm{a}} \pm 1.35$ & $272.1^{\mathrm{e}} \pm 2.11$ & $70.76^{\mathrm{e}} \pm 0.76$ & $1157^{\mathrm{a}} \pm 14.43$ & $0.077^{\mathrm{ab}} \pm 0.003$ & $7.353^{\mathrm{cd}} \pm 1.960$ & $2.70^{\mathrm{c}} \pm 0.70$ \\
LSD & & & & & & & \\
& 2.426 & 2.957 & 4.120 & 23.46 & 0.01731 & 0.6312 & 0.2625 \\
\hline
\end{tabular}

Means, within the same column, followed by the same letter are not significantly different at $<0.05$.

Means are followed by the corresponding standard deviation

Moreover, the groups fish oil and virgin olive oil and mixtures with injection of DEN improved the body weight gain and showed significantly increased when compared with group injection of DEN. The beneficial effect of omega-3 fatty acids administration against DEN poisoning with respect to body weight observed in the present study confirms previous results obtained by [4] who concluded that feeding rats with omega-3 fatty acids could play an important role as a prophylactic against the toxic effects of DEN. Moreover, effects of olive oil may be attributed to its abundant concentration of the monounsaturated fat oleic acid [16] and polyphenolic components [17] to be responsible for this antioxidant effect. Meanwhile, there were no significant differences in liver relative organs weight in rats feed on ration mixed with fish oil and virgin olive oil and mixtures (with or without injection of diethylnitrosamine) compared with control (N1) group. On contrary, there were increased significant differences in liver relative organs weight in rats feed on silymarin and rats injected (DEN) (N2) in Table (2).
[44, 45 and 46] who reported that relative organs weight were significantly increased after injection with (DEN).

Effect of fish oil and virgin olive oil on the serum lipid profile levels in experimental injected with den rats: Total cholesterol and triglyceride concentrations did not induce changes in the serum of rats given fish oil, virgin olive oil and mixed with fish oil and virgin olive oil at concentration $5 \mathrm{~g} / 100 \mathrm{~g}$ diet for 60 successive days than the control (N1) group. The oxidation stress (injected with DEN) significantly increased elevation $(114.12,359.75,179.83$ and $178.32 \%)$, respectively in serum total cholesterol (TC), low density lipoprotein (LDL-C), very low density lipoprotein cholesterol (VLDL - C) and triglycerides(TG) .While HDL- cholesterol was significantly decreased elevation $(28.14 \%)$, as shown in Table ( 3 ). Administration of the tested antioxidants improved or returned these values to the normal ones. These results are agreement with [10]. [47] who reported that TC and TG were significantly increased after treated rats with Diethylnitrosamine (DEN).

Table (3). Effect of fish oil and virgin olive oil serum total cholesterol, (HDL), (LDL), (VLDL) and triglycerides levels in experimental injected with DEN rats.

\begin{tabular}{llllll}
\hline Treatments & TC $(\mathbf{m g} / \mathbf{d l})$ & HDL-C $(\mathbf{m g} / \mathbf{d l})$ & LDL-C $(\mathbf{m g} / \mathbf{d l})$ & VLDL-C $(\mathbf{m g} / \mathbf{d l})$ & T.G $(\mathbf{m g} / \mathbf{d l})$ \\
\hline N1(Control normal) & $83.74^{\mathrm{e}} \pm 0.74$ & $46.83^{\mathrm{a}} \pm 0.83$ & $23.60^{\mathrm{e}} \pm 0.60$ & $13.19^{\mathrm{e}} \pm 0.17$ & $66.29^{\mathrm{e}} \pm 0.29$ \\
N2 (control DEN) & $179.30^{\mathrm{a}} \pm 1.26$ & $33.65^{\mathrm{e}} \pm 1.48$ & $108.50^{\mathrm{a}} \pm 0.30$ & $36.91^{\mathrm{a}} \pm 0.31$ & $184.50^{\mathrm{a}} \pm 1.53$ \\
N3 & $122.70^{\mathrm{b}} \pm 0.71$ & $37.62^{\mathrm{d}} \pm 1.62$ & $\pm 0.6057 .60^{\mathrm{b}}$ & $27.35^{\mathrm{b}} \pm 0.35$ & $136.70^{\mathrm{b}} \pm 1.74$ \\
N4 & $117.60^{\mathrm{c}} \pm 0.58$ & $41.63^{\mathrm{c}} \pm 0.63$ & $51.40^{\mathrm{c}} \pm 0.40$ & $24.26^{\mathrm{c}} \pm 0.26$ & $121.30^{\mathrm{c}} \pm 1.29$ \\
N5 & $117.20^{\mathrm{cd}} \pm 1.23$ & $41.85^{\mathrm{bc}} \pm 0.85$ & $51.20^{\mathrm{c}} \pm 0.20$ & $24.14^{\mathrm{cd}} \pm 0.34$ & $120.70^{\text {cd } \pm 1.68}$ \\
N6 & $116.80^{\mathrm{d}} \pm 0.76$ & $42.37^{\mathrm{b}} \pm 1.37$ & $50.30^{\mathrm{d}} \pm 0.30$ & $24.03^{\mathrm{d}} \pm 0.23$ & $12.20^{\mathrm{d}} \pm 1.16$ \\
N7 & $0.80 \quad 83.80^{\mathrm{e}} \pm$ & $46.65^{\mathrm{a}} \pm 0.65$ & $23.64^{\mathrm{e}} \pm 0.040$ & $13.34^{\mathrm{e}} \pm 0.061$ & $66.53^{\mathrm{e}} \pm 0.53$ \\
N8 & $83.69^{\mathrm{e}} \pm 0.69$ & $47.00^{\mathrm{a}} \pm 0.50$ & $23.35^{\mathrm{ef}} \pm 0.05$ & $13.20^{\mathrm{e}} \pm 0.10$ & $66.00^{\mathrm{e}} \pm 0.50$ \\
N9 & $83.60^{\mathrm{e}} \pm 1.60$ & $47.20^{\mathrm{a}} \pm 0.70$ & $3.10^{\mathrm{f}} \pm 0.802$ & $13.23^{\mathrm{e}} \pm 0.13$ & $66.13^{\mathrm{e}} \pm 0.63$ \\
LSD & & & & 0.1896 & 0.9668 \\
\end{tabular}

Means, within the same column, followed by the same letter are not significantly different at $<0.05$.

Means are followed by the corresponding standard deviation. 
Effect of fish oil and virgin olive oil on the liver functions levels in experimental injected with den rats: The obtained results showed that feeding on ration mixed with fish oil, virgin olive oil and mixed with fish oil and virgin olive oil at concentration $5 \mathrm{~g} / 100 \mathrm{~g}$ diet for 60 successive days did not induce changes in serum AST, ALT and ALP when compared with control N1 group. Administration of N2 (injected with DEN) produced significant adverse effects on the liver functions of the rats, which is evidenced by a significant increase (206.59, 232.33 and $328.34 \%$, respectively) in the activities of ALT, AST and ALP enzymes as compared to control group (N1) in Table (4). Nitrosamine is absorbed in intestine and enters the liver and hepatocytes by portal venous system, and hampers the detoxification system of liver by interfering in cytochrome P450 enzymes, so, the liver gently proceeds to cirrhosis and cancer. When DEN is formed, it leads to lipid peroxidation of the polyunsaturated fatty acid in cell membranes, break down of membrane - structure and leading to the release of microsomal corboxyal esterase and other enzymes, such as amino transferases in to the extra cellular compartments including serum [46]. These results agree with previous studies of [4] who found that antioxidant enzymes activities (GSPHx, Catalase and SOD) levels were decreased significantly following injected DEN exposure. Treatment of (with injected DEN of rats with silymarin and (fish oil, virgin olive oil and mixed with fish oil and virgin olive oil) exhibited improvement in liver functions compared to N2 group (intraperitoneally injected with DEN) rats. These results may attribute to the presence of omega-3 fatty acids of fish oil and virgin olive oil which had important beneficial effects on the liver regeneration. [48] who reported that rats feeding silymarin with injected DEN were significantly decreased liver function. Meanwhile, Feeding on ration mixed with fish oil, virgin olive oil and mixed with fish oil and virgin olive oil at concentration $5 \mathrm{~g} / 100 \mathrm{~g}$ diet for 60 successive days did not induce changes of serum total protein, albumin and total bilirubin when compared with control normal group. These results are agreement with [4]. Injection of DEN caused significantly decreased in serum total protein and albumin. Our results agree with [49] who found that injection of DEN for 2 months to rats showed significantly decreased the level of total protein and albumin. In conclusion, the results in this study showed significant decreases in total protein, and albumin, which may be due to impaired kidney and liver function. Because albumin is synthesized by the liver, decreased albumin may result from liver damage. It can also result from kidney disease, which allows albumin to escape into the urine [50] and also, the major site of synthesis of the plasma proteins is the liver and the second major site is the immune system. Rats feed on ration mixed with fish oil, virgin olive oil and injected DEN showed significant increase in total protein and albumin directed toward normal value. The obtained data are agreement with [24]. This is useful for reduces chronic liver injury and liver fibrosis in rats with liver injury induced by DEN.

Table (4). Effect of fish oil and virgin olive oil on the liver functions levels in experimental injected with DEN rats.

\begin{tabular}{|c|c|c|c|c|c|c|}
\hline \multirow{2}{*}{ Treatments } & \multicolumn{6}{|c|}{ Liver functions } \\
\hline & ALT (U/L) & $\operatorname{AST}(\mathbf{U} / \mathbf{L})$ & $\operatorname{ALP}(\mathbf{U} / \mathbf{L})$ & Total protein $(\mathrm{mg} / \mathrm{dl})$ & Albumin (mg/dl) & Total bilirubin (mg/dl) \\
\hline N1(Control normal) & $24.86^{\mathrm{e}} \pm 4.86$ & $29.66^{\mathrm{e}} \pm 1.660$ & $69.71^{\mathrm{e}} \pm 2.710$ & $7.92^{\mathrm{ab}} \pm 0.92$ & $4.29^{\mathrm{a}} \pm 0.29$ & $0.54^{\mathrm{e}} \pm 0.16$ \\
\hline N2 (control DEN) & $76.22^{a} \pm 3.22$ & $98.57^{\mathrm{a}} \pm 3.570$ & $298.60^{\mathrm{a}} \pm 3.650$ & $3.84^{\mathrm{g}} \pm 0.84$ & $2.82^{\mathrm{c}} \pm 0.82$ & $0.87^{\mathrm{a}} \pm 0.17$ \\
\hline N3 & $54.63^{\mathrm{b}} \pm 4.63$ & $67.85^{\mathrm{b}} \pm 2.850$ & $242.50^{\mathrm{b}} \pm 4.52$ & $5.49^{\mathrm{f}} \pm 0.49$ & $3.54^{\mathrm{b}} \pm 0.54$ & $0.76^{\mathrm{b}} \pm 0.16$ \\
\hline N4 & $24.70^{\mathrm{e}} \pm 1.70$ & $29.75^{\mathrm{e}} \pm 2.750$ & $69.65^{\mathrm{e}} \pm 1.650$ & $5.88^{\mathrm{e}} \pm 0.88$ & $3.70^{\mathrm{b}} \pm 0.70$ & $0.68^{\mathrm{c}} \pm 0.18$ \\
\hline N5 & $24.95^{\mathrm{e}} \pm 0.95$ & $29.80^{\mathrm{e}} \pm 1.800$ & $69.90^{\mathrm{e}} \pm 2.900$ & $6.23^{\mathrm{d}} \pm 0.23$ & $3.76^{\mathrm{b}} \pm 0.76$ & $0.63^{\mathrm{cd}} \pm 0.13$ \\
\hline N6 & $24.65^{\mathrm{e}} \pm 2.65$ & $29.40^{\mathrm{e}} \pm 3.400$ & $69.45^{\mathrm{e}} \pm 4.450$ & $6.40^{c} \pm 0.40$ & $3.83^{b} \pm 0.83$ & $0.61^{\mathrm{cd}} \pm 0.11$ \\
\hline N7 & $39.81^{c} \pm 2.81$ & $58.66^{c} \pm 3.657$ & $146.30^{\mathrm{c}} \pm 1.340$ & $8.05^{\mathrm{a}} \pm 0.55$ & $4.45^{\mathrm{a}} \pm 0.45$ & $0.57^{\mathrm{de}} \pm 0.06$ \\
\hline N8 & $40.44^{\mathrm{c}} \pm 0.44$ & $60.14^{c} \pm 2.140$ & $147.30^{c} \pm 1.260$ & $7.98^{\mathrm{ab}} \pm 0.48$ & $4.53^{\mathrm{a}} \pm 0.33$ & $0.55^{\mathrm{e}} \pm 0.05$ \\
\hline N9 & $35.73^{d} \pm 2.73$ & $51.29^{\mathrm{d}} \pm 1.290$ & $139.20^{d} \pm 3.19$ & $7.90^{\mathrm{b}} \pm 0.90$ & $4.60^{\mathrm{a}} \pm 0.30$ & $0.59^{\mathrm{de}} \pm 0.14$ \\
\hline \multicolumn{7}{|l|}{ LSD } \\
\hline & 2.584 & 1.527 & 2.153 & 0.1341 & 0.3909 & 0.07741 \\
\hline
\end{tabular}

Means, within the same column, followed by the same letter are not significantly different at $<0.05$

Means are followed by the corresponding standard deviation

Effect of fish oil, virgin olive oil and mixed with fish oil and virgin olive oil on serum (MDA) and on erythrocyte (SOD, Catalase, GSPx and GSH) levels in experimental injected with den rats: Table (5) show the activity levels of serum malonaldehyde (MDA), enzymatic antioxidants, SOD, Catales, GSH-Px and non-enzymatic antioxidant, GSH in erythrocyte, respectively, in normal and experimental rat groups. MDA, SOD, Catales, GSH-Px and GSH did not induce changes in the rats given fish oil, virgin olive oil and mixed with fish oil and virgin olive oil at concentration $5 \mathrm{~g} / 100 \mathrm{~g}$ diet for 60 successive days than the control (N1) group. These results agree with [19 and 51]. The activities of serum maloaldehyde (MDA) activity was significantly increased ( $191.54 \%$ ) in rat injected with DEN group (control) 
compared to normal(control). While the activities of enzymatic antioxidants (SOD, Catalase, GSH-Px) and non-enzymatic antioxidant (GSH reduced) were significantly decreased (46.99, 35.02, 55.88 and $34.84 \%$, respectively) in rats injected with DEN group (control), when compared with the normal group. Supplemented of the experimental injected with DEN rat groups with fish oil ,virgin olive oil and mixed with fish oil and virgin olive oil increased the activities of enzymatic antioxidant, (SOD, Catales, GSH-Px) and non-enzymatic antioxidant, GSH reduced level [24]. Hepatic injury induced by DEN was associated with oxidative stress due to DEN -induced free radical production and toxic. Oxidative stress plays an important role in chronic complications of injected with DEN and is postulated to be associated with increased lipid peroxidation [52]. The cytotoxic action of injected with DEN is associated with the generation of reactive oxygen species causing oxidative damage [53]. The increased free radicals produced may react with polyunsaturated fatty acids in cell membranes leading to lipid peroxidation. Lipid peroxide-mediated damage has been observed in the development of injected with DEN. The increased lipid peroxidation in the serum of injected with DEN animals may be due to the observed remarkable increase in the concentration of free radical in the serum of injected with DEN rats.

In the current study, level of serum MDA injected with DEN groups supplemented with fish oil, virgin olive oil and mixed with fish oil and virgin olive oil at concentration $5 \mathrm{~g} / 100 \mathrm{~g}$ diet for 60 successive days showed a significant reduction which indicates a decreased rate of lipid peroxidation [19 and 51]. In general, superoxide dismutase (SOD) is an important antioxidant enzyme which catalyzes the conversion of toxic superoxide radical to less reactive hydrogen peroxide [54] .SOD is known to be reduced markedly in DEN induced hepatic injury [55]. While oxidative stress could be ameliorated via the elevation of hepatic SOD level [56] .In addition, glutathione peroxidase (GPx) is another antioxidant enzyme commonly used to investigate the oxidative stress [3]. It has been indicated that antioxidant-like compounds produce hepatic protection through an increase in GPx to scavenge the free radicals [19].

Table (5). Effect of fish oil and virgin olive oil on serum (MDA) and on erythrocyte (SOD, Catalase, GSPx and GSH) levels in experimental injected with DEN rats.

\begin{tabular}{llllll}
\hline Treatments & SOD $(\mathbf{U} / \mathbf{m l})$ & Catalase $(\mathbf{U} / \mathbf{m l})$ & GSPx $(\mathbf{U} / \mathbf{m l})$ & GSH $(\mathbf{m g} / \mathbf{d l})$ & MDA $(\mathbf{n m o l} / \mathbf{m l})$ \\
\hline N1(Control normal) & $315.8^{\mathrm{a}} \pm 2.750$ & $142.30^{\mathrm{a}} \pm 2.330$ & $176.40^{\mathrm{a}} \pm 4.410$ & $40.95^{\mathrm{a}} \pm 2.950$ & $11.83^{\mathrm{d}} \pm 1.830$ \\
N2 (control DEN) & $167.40^{\mathrm{a}} \pm 2.380$ & $92.46^{\mathrm{e}} \pm 2.460$ & $77.82^{\mathrm{e}} \pm 2.820$ & $26.68^{\mathrm{e}} \pm 2.680$ & $34.49^{\mathrm{a}} \pm 4.490$ \\
N3 & $254.60^{\mathrm{d}} \pm 4.610$ & $111.50^{\mathrm{d}} \pm 1.530$ & $138.30^{\mathrm{d}} \pm 3.290$ & $\pm 2.54030 .54^{\mathrm{c}}$ & $19.67^{\mathrm{b}} \pm 2.670$ \\
N4 & $316.10^{\mathrm{a}} \pm 1.110$ & $142.80^{\mathrm{a}} \pm 2.810$ & $177.40^{\mathrm{a}} \pm 2.360$ & $41.35^{\mathrm{a}} \pm 1.350$ & $10.90^{\mathrm{d}} \pm 0.900$ \\
N5 & $315.90^{\mathrm{a}} \pm 3.870$ & $142.60^{\mathrm{a}} \pm 2.650$ & $176.70^{\mathrm{a}} \pm 1.680$ & $40.86^{\mathrm{a}} \pm 1.860$ & $11.26^{\mathrm{d} \pm 1.760}$ \\
N6 & $316.80^{\mathrm{a}} \pm 3.760$ & $143.20^{\mathrm{a}} \pm 3.160$ & $177.80^{\mathrm{a}} \pm 2.800$ & $41.69^{\mathrm{a}} \pm 1.690$ & $10.65^{\mathrm{d}} \pm 0.650$ \\
N7 & $272.30^{\mathrm{c}} \pm 2.280$ & $125.60^{\mathrm{c}} \pm 3.640$ & $163.20^{\mathrm{bc} \pm 3.210}$ & $35.68^{\mathrm{b}} \pm 2.680$ & $15.94^{\mathrm{c}} \pm 1.940$ \\
N8 & $271.50^{\mathrm{c}} \pm 1.550$ & $124.90^{\mathrm{c}} \pm 2.950$ & $161.70^{\mathrm{c}} \pm 1.730$ & $35.19^{\mathrm{b}} \pm 2.190$ & $15.52^{\mathrm{c}} \pm 0.520$ \\
N9 & $289.80^{\mathrm{b}} \pm 3.820$ & $136.40^{\mathrm{b}} \pm 1.380$ & $163.50^{\mathrm{b}} \pm 3.540$ & $36.22^{\mathrm{b}} \pm 1.220$ & $14.77^{\mathrm{c}} \pm 4.770$ \\
LSD & & & & 1.086 & \\
\end{tabular}

Means, within the same column, followed by the same letter are not significantly different at $<0.05$.

Means are followed by the corresponding standard deviation.

Figure (1) showed the microscopic estimation of the liver of the tested rat groups. Control (N1), untreated rat group revealed a normal histological structure of hepatic lobule (Slide 1). Meanwhile, liver of rat from group injected with DEN group (N2) showed cytoplasmic vacuolization of hepatocytes(Slide 2), foci of clear cells (Slide 3) and karyomegaly of some hepatocytic nuclei (Slide 4 and 5) . However, liver of rat from group silymarin (drug) showed foci of clear cells (Slide 6) and cytoplasm vacuolization of hepatocytes (Slide 7) [57] .Meanwhile, liver of rat from group (N7) showed slight activation of kupffer cells (Slide 8). In addition, liver of rat from groups (N4, N5 and N6) showed no changes with apparent normal hepatocytes (Slide 1).

In the present study concluded that the concentration of lipid peroxidation is a successful indicator to the increment of free radicals in the injected with DEN rats. Consequently, administration of fish oil and virgin olive oil significantly declined the levels of lipid peroxidation and thus prevent tissue damage.

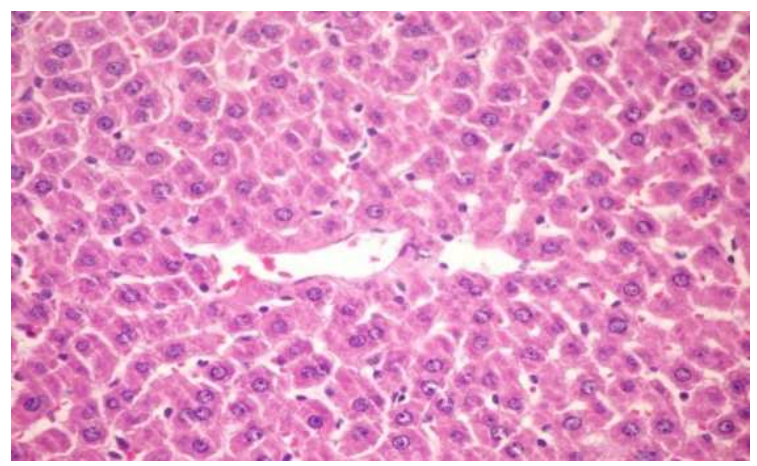

Slide (1): Control group(N1) 


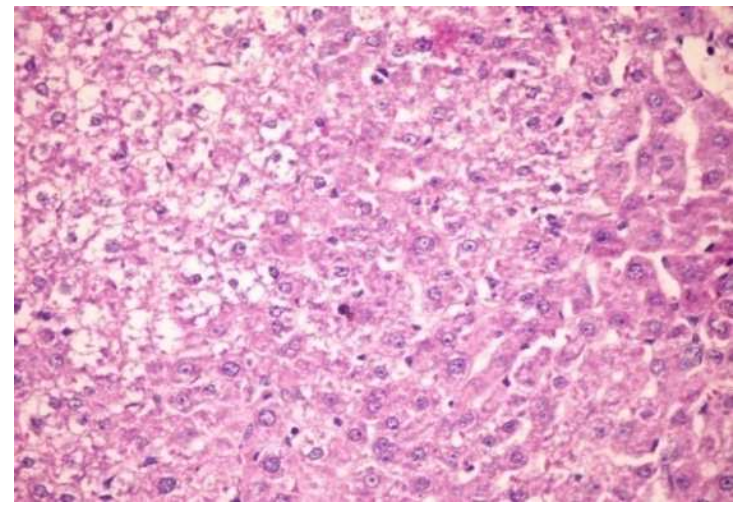

Slide (2): Control DEN group (N 2)

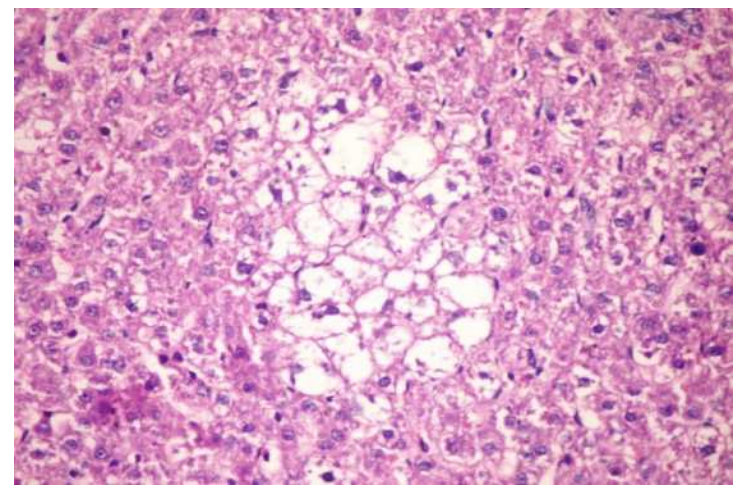

Slide (3): Control DEN group (N 2)

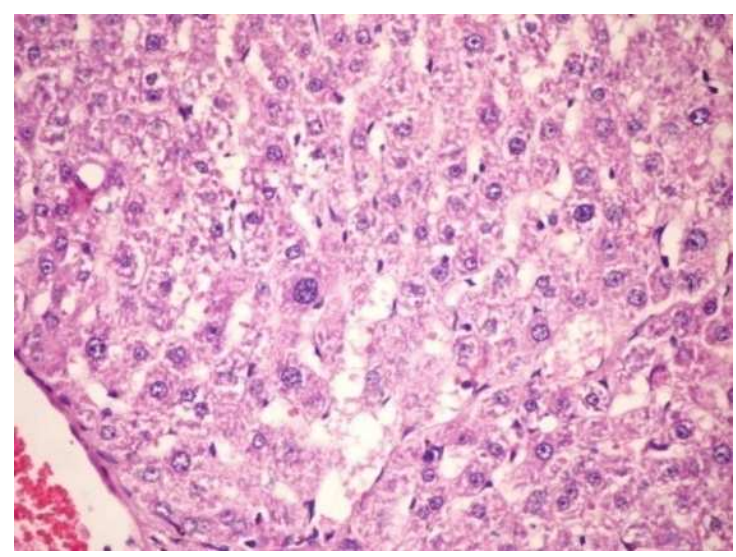

Slide (4): Control DEN group (N 2)

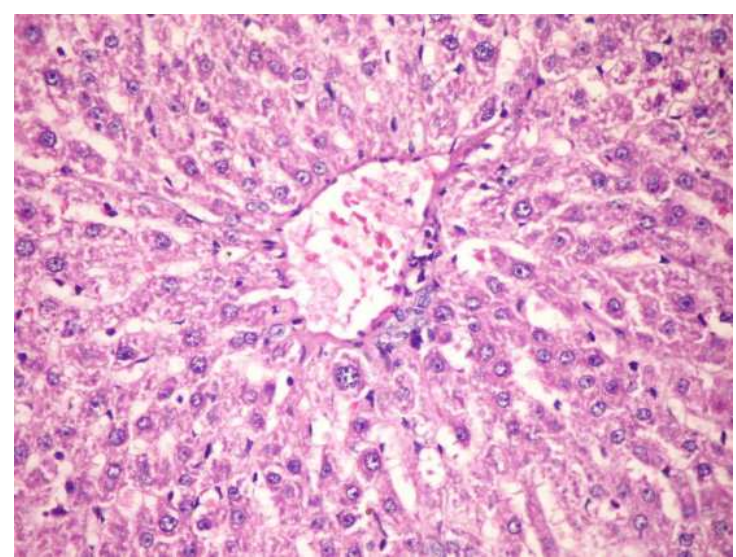

Slide (5): Control DEN group (N 2)

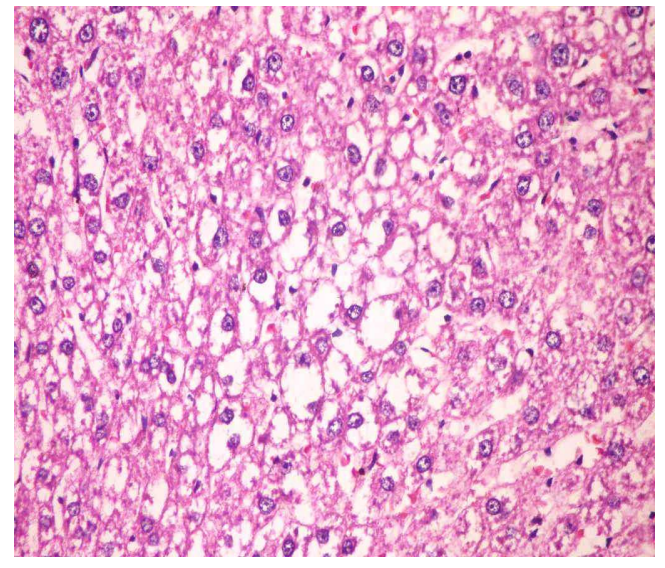

Slide (6): Drug group (N3)

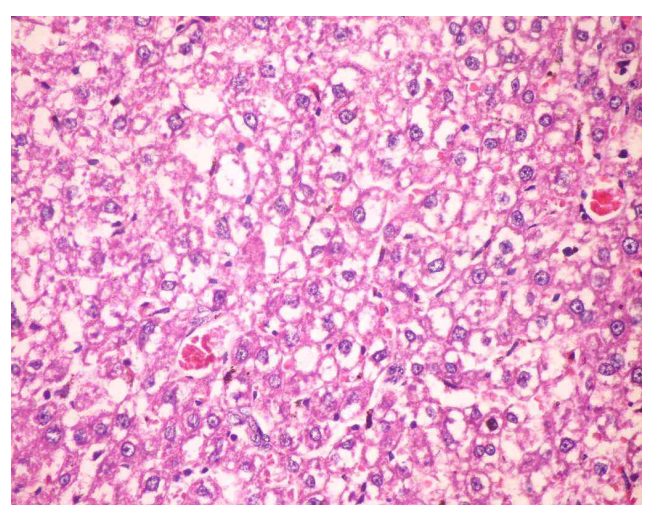

Slide (7): Drug group (N3)

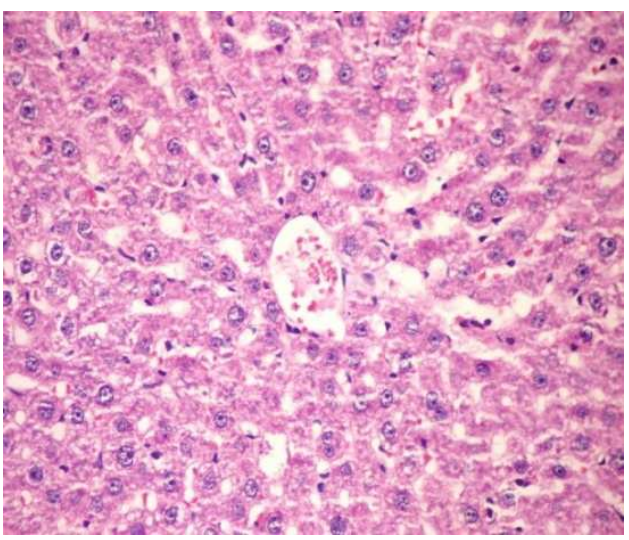

Slide (8): group (N7)

Figure (1). Histopathological changes in tissue section of liver.

\section{References}

[1] Veena, S. and Manu, S., (2012). N-nitrosodimethylamine as a hazardous chemical toxicant in drinking water. International Research Joournal of Pharmacy.3(3):60-65.

[2] Srigopalram, S. and Jayraaj, Indira A., (2012). Effect of terminalia chebula retz on den induced hepatocellular carcinogenesis in experimental rats. International Journal of Pharmacy and Pharmaceutical Sciences. Vol 4, Issue 2, 440-445. 
[3] Nermin A. H. S.; Shohda A. E. and Manal F. I., (2008). Diethylnitrosamine-induced hepatocarcinogenesis in rats: possible chemoprevention by blueberries. African Journal of Biochemistry Research ,Vol.2, (3): 081-087.

[4] Atakisi, O.; Atakisi, E. ;Ozcan, A.; Karapehlivan, M. and Kart, A., (2013). Protective effect of omega-3 fatty acids on diethylnitrosamine toxicity in rats. European Review for Medical and Pharmacological Sciences, 17: 467-471.

[5] Singh, A.; Bhat, T. K. and Sharma, O.P., (2011). Clinical Biochemistry of Hepatotoxicity. J Clinic Toxicol, S: 4, 1-19.

[6] Calvisi , D., F. ; Sara, L.; Hironaka, K.; Factor, V., M. and Thorgeirsson, S. S., (2004). Vitamin E down-modulates iNOS and NADPH oxidase in c-Myc/TGF-a transgenic mouse model of liver cancer. Journal of Hepatology, 41: 815-822.

[7] Hussain, S.P.; Hofseth, L.J. and Harris, C.C., (2003) .Radical causes of cancer. Nature Reviews Cancer, 3:276-285.

[8] Lenihan-Geels, G.; Bishop, K., S. and Ferguson, L. R., (2013). Alternative Sources of Omega-3 Fats: Can We Find a Sustainable Substitute for Fish? Nutrients ,5: 1301-1315.

[9] Simopoulos, Artemis P.; MD and, FACN (2002). Omega-3 fatty acids in inflammation and autoimmune diseases. Journal of the American College of Nutrition, Vol. 21: 6, 495-505.

[10] Gazi, I.; Liberopoulos , E. , N.; Saougos , V. , G. and Elisaf , M. , (2006). Beneficial effects of Omega-3 fatty acids: The current evidence. Hellenic J Cardiol 47: 223-231.

[11] Jing; W., T. and Lim, K., (2013). Omega-3 polyunsaturated fatty acids and cancer. Anti-Cancer Agents in Medicinal Chemistry, 13, 1162-1177.

[12] Mazza , M. ; Pomponi, M.; Janiri, L. ; Bria, P. and Mazza, S., (2007). Omega-3 fatty acids and antioxidants in neurological and psychiatric diseases: An overview. Progress in Neuro-Psychopharmacology \& Biological Psychiatry 31, $12-26$.

[13] Patten A. R.; Brocardo, P. S. and Christie, B. R., (2013). Omega-3 supplementation can restore glutathione levels and prevent oxidative damage caused by prenatal ethanol exposure. Journal of Nutritional Biochemistry, 24, 760-769.

[14] Vauzour, D. ; Rodriguez- Mateos, A. ; Corona, G.; Oruna Concha, M. J. and Spencer, J. P. E., (2010). Polyphenols and Human Health: Prevention of Disease and Mechanisms of Action. Nutrients, , 1106-1131.

[15] Lo'pez-Miranda , J. ; Pe'rez-Jime'nez F.; Ros E.; De Caterina R. ; Badimo'n L.; Covas M.I. ; Escrich E. ; Ordova's J.M. ; Soriguer F. ; Abia R. ' ; Alarco'n de la Lastra C.; Battino M. ; Corella D.; Chamorro-Quiro's J. ; Delgado-Lista J. ; Giugliano D.; Esposito K.; Estruch R.; Fernandez-Real J.M.; Gaforio J.J.; La Vecchia C.; Lairon D.; Lo'pez-Segura F.; Mata P. ; Mene'ndez J.A. ; Muriana F.J., Osada J.; Panagiotakos D.B. ; Paniagua J.A.; Pe'rez-Martinez P.; Perona J. ; Peinado M.A.; Pineda-Priego M.; Poulsen H.E.; Quiles J.L.; Ramı'rez-Tortosa M.C. ; Ruano J.; Serra-Majem L. ; Sola R.' ; Solanas M. ; Solfrizzi V. ; de la Torre-Fornell R.; Trichopoulou A. ; Uceda M. ; Villalba-Montoro J.M.; Villar-Ortiz J.R. ; Visioli F.; Yiannakouris N. , (2010). Olive oil and health: Summary of the II international conference on olive oil and health consensus report, Jae'n and Co'rdoba (Spain) 2008. Nutrition, Metabolism \& Cardiovascular Diseases, 20, 284-294.
[16] Pérez-Martínez, P.; Antonio G.; Javier D.; Francisco P. and José L., (2011). Mediterranean diet rich in olive oil and obesity, metabolic syndrome and diabetes mellitus. Current Pharmaceutical Design, 17, 1-9.

[17] Servili, M.; Sordini B.; Esposto S.; Urbani S.; Veneziani G.; Di Maio I.; Selvaggini R. and Taticchi A., (2011). Biological Activities of Phenolic Compounds of Extra Virgin Olive Oil. Antioxidants , 3, 1-23.

[18] Omar, S. H., (2010). Oleuropein in olive and its pharmacological effects. Sci Pharm., 78: 133-154.

[19] Abir K. ; Amel N. ; Nadia K. ; Saloua E.; Najoua G.; Abdelaziz K. and Mohamed H., (2008). Dietary virgin olive oil protects against lipid peroxidation and improves antioxidant status in the liver of rats chronically exposed to ethanol. Nutrition Research 28,472-479.

[20] Aura, A. M.; Forssell, P.; Mustranta, A. and Poutanen, K. (1995). Transesterification of soy lecithin by lipase and phosphilipase .J. Am. Oil Chem.Soci., 72: (11): 1375-1379.

[21] Lane Peter, W. and Person, A.E.G. (1971). Dietary Requirements in the Laboratory: Animal Principles and Practice, Acad. Press, London and New York. p142.

[22] Hegested, D.M.; Mills, R.C.; Elvehijem, C.A. and Hart, F.B., (1941). Choline in the nutrition of check. J. Biol. Chem., 138: 459.

[23] Camplell , T.A. , (1961). Methodology of protein evaluation. RAG. Nutr. Document R.101 adds. 37, June Melting, New York.

[24] Metwally, N.S.; Kholeif, T.E.; Ghanem, K.Z.; Farrag, A.R.H.; Ammar, N.M. and Abdel-Hamid, A.H.Z., (2011). The protective effects of fish oil and artichoke on hepatocellular carcinoma in rats. European Review for Medical and Pharmacological Sciences, 15: 1429-1444.

[25] Waston, D.A., (1960). Simple method for the determination of serum cholesterol. Clin. Chem. Acta., 5:589-596.

[26] Assmann, G., (1979). A fully enzymatic colorimetric determination of HDL-cholesterol in the serum. Internist, 20: 559-565.

[27] Wieland, H. and Seidel, D., (1983). A fully enzymatic colorimetric determination of HDL-cholesterol in the serum. J. Nutr., 109: 760 - 766.

[28] Wallach, J., (1992). Interpretation of Diagnostic Tests. A synopsis of aboratory medicine, $5^{\text {th } \mathrm{Ed}}$. A little brown handbook, Boston.

[29] Fossati, P. and Prencipe, L., (1982). The determination of triglycerdes using enzymatic methods. Clin. Chem., 28: $2077-$ 2081.

[30] Bergmeyer, H. U. and Harder, M., (1986). A colorimeteric method of determination of serum glutamic oxaloacetic and glutamic pyruvic transaminase. Clin. Biochem., 24: 28 - 34.

[31] Varley, H.; Gewenlock, A. and Bell, M., (1980). Practical Clinical Biochemistry. vol. 1. 5th ${ }^{\text {ed., }}$ pp. 741, 897. London: William Heinemen Medical. Books, Ltd.

[32] Sonnenwirth, A. and Jaret, L. (1980). Grad wholes clinical laboratory mehods and diagnosis.vol. $18^{\text {th }}$ edMosby.London. 
[33] Drupt, F. (1974). Colorimetric method for determination of albumin. Pharm. Biol., 9: 777-779.

[34] Kaplan L.A. and Pesce A.J., (1984). Clinical chemistry: theory, analysis, and correlation (pp 1032-6). St. Louis, MO: Mosby.

[35] Meltzer, H.M.; Folmer, M.; Wang, S.; Lie, Q.; Maage, A. and Mundal, H.H., (1997). Supplementary selenium influences the response to fatty acid induced oxidative stress in humans. Biological Trace Element Research, 60: 51-67.

[36] Nishikimi, M.; Roa, N.A. and Yog, K., (1972). The occurrence of superoxide anion in the reaction of reduced phenazine methosulphate and molecular oxygen. Biochem.Bioph. Res. Common., 46: 849-854.

[37] Aebi , H., (1984). Catalase in vitro. Methods Enzymol .,105:121-136.

[38] Rotruck. J.J.; Pope, A. L.; Ganther, H.E. and Swanson, A.B., (1973). Selenium: biochemical role as a component of glutathione peroxidase. Science, 179: 588-590.

[39] Ellman, G.L., (1959). Tissue sulfhydrl groups. Archieves of Biochem. and Biophys., 82: 70-77.

[40] Yoon, B.I.; Choi, Y.K. ; Kim, D.Y.; Hyun, B.H.; Joo, K.H.; Rim, H.J. and Lee, J.H., (2001). Infectivity and pathological changes in murine clonorchiasis: Comparison in immunocompetent and immunodeficient mice. J. Vet. Med. Sci., 63(4): 421-425.

[41] Snedecor, G.W. and Cochran, W.G., (1980). Statistical methods $7^{\text {th Ed., }}$ p. 420. Iowa Stat. Univ. Press, Ames, Iowa, USA.

[42] Hamadani, M.; Asadiagajari M.; Vahdatpour T.; Bahrami Y.; Salehzadeh K. and Vahdatpour S., (2011). Efficiency of dietary fish oil for regulation of hyperlipidemia and hyperglycemia in diabetic rats. Annals of Biological Research, 2(3):75-81.

[43] Sreepriya M. and Bali G., (2005). Chemopreventive effects of curcumin against N-nitrosodiethylamine/ phenobarbital-induced hepatocarcinogenesis in Wistar rats. Fitoterapia, 76: 549-555.

[44] Sivaramakrishnan, V; Pnm, S. ; Vrp, K. and Devaraj SN., (2008). Attenuation of N-nitrosodiethylamine-induced hepatocellular carcinoma by a novel flavonol-Morin. Chem Biol Interact, 171: 79- 88.

[45] Cecen, E.; Dost, T.; Culhaci, N.; Karul, A.; Ergur, B. and Birincioglu, M., (2011). Protective effects of silymarin against doxorubicin-induced toxicity .Asian Pacific Journal of Cancer Prevention, 12,2697-2704.

[46] Uehara, T.; Ainslie G.R.; Kutanzi K.; Pogribny I. P.; Muskhelishvili L.; Izawa; J. Yamate T.; Kosyk O.; Shymonyak S.; Bradford B. U.; Boorman G.A.; Bataller R. and Rusyn I., (2013). Molecular Mechanisms of Fibrosis-Associated Promotion of Liver Carcinogenesis. Toxicological sciences 132(1), 53-63.
[47] Ramalingam, R. and Vaiyapuri, M., (2014). Umbelliferone with vitamin $\mathrm{C}$ modulatea lipid profile indices in diethylnitrosamine induced hepatocellular carcinoma.Journal of Biological \&Scientific Opinion,2(6),384-389.

[48] Imamoto, R. ; Okano J.; Sawada S.; Fujise Y. ; Abe R. and Murawaki Y., (2014). Null anticarcinogenic effect of silymarin on diethylnitrosamine-induced hepatocarcinogenesis in rats. Experimental and Therapeutic Medicine, 7: 31-38.

[49] Ahmed, O. M.; Mohamed B. A.; Hanaa I. F.; Ayman M. M. and Noha A. A., (2014). Preventive effect of spirulina versicolor and enteromorpha flexuosa ethanolic extracts against diethylnitrosamine/benzo (a) pyrene-induced hapatocarcinogencity in rats. Journal of international Academic Research for Multidisciplinary, 2, 7: 633-650.

[50] Thanaa, A. E.; Naglaa, H. M. H. and Hanan, Y.A., (2013). Hepatoprotective effects of the mushroom (shiitake "Lentinus-edodes) against Carbon-Tetrachloride-Induced liver injury in rats. Health MED, 7(8):2385-2394.

[51] Tulubas, F.; Gurel A.; Oran M.; Topcu B.; Caglar V. and Uygur E., (2013). The protective effects of o-3 fatty acids on doxorubicin-induced hepatotoxicity and nephrotoxicity in rats. Toxicology and Industrial Health,1-7.

[52] Rezaie , A. ; Pashmforosh M.; Karamallah M. H.; Fazlara A.; Haghighat N. and Shahriari A., (2014). Hepatoprotective effect of caffeine on diethylnitrosamine-induced liver injury in rats. Bulgarian Journal of Veterinary Medicine, 17: 3, 183-190.

[53] Erejuwa, O. O.; Sulaiman S. A. and Ab Wahab M. S., (2014). Effects of honey and its mechanisms of action on the development and progression of cancer.Molecules, 19, 2497-2522.

[54] Kim, B. M. ; Rhee, J. S. ; Park, G. S.; Lee, J.; Lee, Y.M. and Lee, J. S. (2011). "Cu/Zn- andMn-superoxide dismutase (SOD) fromthe copepod Tigriopus japonicus: molecular cloning and expression in response to environmental pollutants," Chemosphere, vol. 84, (10): 1467-1475.

[55] Chen, M.; Chung, H. and Lu, H. ,(2012). Protection of the Extracts of Lentinus edodes Mycelia against Carbon-Tetrachloride-Induced Hepatic Injury in Rats. The ScientificWorld Journal,vol. 2012:1- 8.

[56] Meganathan, M.; Gopal K. M.; Sasikala P.; Mohan J.; Gowdhaman N .; Balamurugan K.; Nirmala P. and Samuel V., (2011). Evaluation of antioxidant effect of Omega 3-fatty acid against paracetamol induced liver injury in albino rats. Research Journal of Pharmaceutical, Biological and Chemical Sciences, 2,426-433.

[57] Rezaie, A. ; Fazlara A.; Karamolah M. H.; Shahriari A.; Zadeh H. N. and Pashmforosh M., (2013). Effect of Echinacea purpurea on hepatic and renal toxicity induced by diethylnitrosamine in rats. Jundishapur J Nat Pharm Prod., 8(2), 60- 64 . 